\title{
МАТЕМАТИЧЕСКАЯ МОДЕЛЬ КИНЕТИКИ УВЛАЖНЕНИЯ ЗЕРНА КРУПЯНЫХ КУЛЬТУР ПРИ ГИДРОТЕРМИЧЕСКОЙ ОБРАБОТКЕ
}

\author{
А. А. Румянцев
}

В статье приведен метод описания процесса увлажнения зерна при гидротермической обработке. Разработанный способ пропаривания перемешиваемого слоя зерна гречихи как насыщенным, так и перегретым паром предполагает в последнем случае в качестве управляемых параметров давление, температуру пара и время обработки. Несмотря на различие в кинетике увлажнения зерна тем или иным способом, ее характер имеет общие тенденции, что создает предпосылки для использования при моделировании процесса общего класса функций. При этом кинетику увлажнения зерна рационально моделировать с помощью упрощенных математических фрункций, обеспечивающих приемлемую точность и удобство интерпретации. Особенностью увлажнения зерна является наличие лимитирующей стадии, идущей значительно медленнее других и ограничивающей скорость всего процесса. При этом кривая увлажнения зерна, рассчитанная по предлагаемой модели, будет иметь характерный для этого процесса вид монотонно возрастающей фрункции, асимптотически приближающейся к некоторому предельному значению, связанному с насыщением зерна влагой при тех или иных способах увлажнения. Предлагаемый тип модели процесса увлажнения зерна позволяет включать самые различные исследуемые фракторы, которые поддаются количественной оценке, а также упростить программное обеспечение при автоматизации прочесса гидротермической обработки зерна.

Ключевые слова: математическая модель, температура, давление, время, увлажнение, пропаривание, гидротермическая обработка, зерно, крупяные культуры, автоматизация

В результате гидротермической обработки (ГТО) крупяных культур анатомические части зерна должны быть приведены в состояние, обеспечивающее, возможно, более полное отделение оболочек (плёнок) при сохранении целостности ядра как в процессе шелушения, так и при последующих операциях его обработки. В связи с этим ГТО сводится в основном к повышению прочности ядра при пропаривании или увлажнении зерна и хрупкости оболочек в процессе последующей сушки.

Степень увлажнения зерна за определенный промежуток времени при воздействии на него влаги зависит не только от его природы и состояния, но и от способов увлажнения и его параметров. Одним из самых распространенных способов увлажнения зерна является его пропаривание насыщенным паром избыточного давления, используемый в традиционной технологии гидротермической обработки зерна. Реже увлажняют зерно холодной или горячей водой, а также насыщенным паром атмосфрерного давления [1-3]. Последовательное использование этих способов увлажнения рекомендуется в некоторых технологических схемах гидротермической об- работки зерна гречихи для малых фермерских хозяйств [4]. Имеются предложения по увлажнению зерна и крупы перегретым паром $[5,6]$. Известно также, что наиболее интенсивным является способ увлажнения горячей водой $[4,7,8]$.

Очевидно, что кинетика увлажнения зерна будет зависеть от набора параметров, сопутствующих тому или иному реализуемому способу обработки зерна влагой, при этом общим параметром для всех способов увлажнения является его продолжительность [9-11]. При пропаривании зерна насыщенным паром, помимо времени, на увлажнение зерна влияет уровень его давления и сопутствующий ему температурный режим, а при увлажнении водой - ее температура. Известно, что чем выше давление насыщенного пара, время пропаривания, начальная влажность и ниже температура зерна, тем выше степень его увлажнения [1-3].

Исследований кинетики увлажнения зерна гречихи различными способами не так много, при этом зачастую они противоречивы и не затрагивают всех сторон процесса. Лишь в последние годы активизируются работы, в которых делается попытка связать степень увлажнения зерна с параметрами пропаривания и 


\section{МАТЕМАТИЧЕСКАЯ МОДЕЛЬ КИНЕТИКИ УВЛАЖНЕНИЯ ЗЕРНА КРУПЯНЫХ КУЛЬТУР ПРИ ГИДРОТЕРМИЧЕСКОЙ ОБРАБОТКЕ}

некоторыми показателями исходного зерна. Как правило, эти исследования завершаются анализом результатов, полученных при отдельных измерениях, из которых невозможно сделать выводы о характере влияния тех или иных показателей на процесс увлажнения, что может оказаться важным при решении задач выбора рациональных режимов гидротермической обработки зерна, а также ее автоматизации.

Разработанный нами способ пропаривания перемешиваемого слоя зерна гречихи как насыщенным, так и несколько перегретым паром предполагает в последнем случае в качестве управляемых параметров давление и температуру пара, а также время [12]

Однако, несмотря на различие в кинетике увлажнения зерна тем или иным способом, ее характер имеет общие тенденции, что создает предпосылки для использования при моделировании процесса общего класса функций.

Изменение текущего влагосодержания зерна в процессе его прогрева насыщенным паром можно найти из теплового баланса, который в этом случае без учета тепла, выделяемого при охлаждении конденсата, будет иметь вид

$$
\Delta U \times r \times \rho_{n}=c_{3} \times \rho_{3} \times\left[\bar{T}(\tau)-T_{0}\right],
$$

где $\Delta U=U(\tau)-U_{\text {н }}-$ избыточная влага зерна при текущем $U(T)$ и начальном $U_{\text {н }}$ влагосодержании, кг/кг;

$r$ - удельная теплота парообразования (конденсации), Дж/кг;

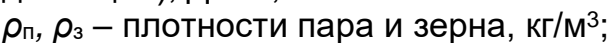
$c_{3}$ - удельная теплоёмкость зерна, Дж/(кг·К); $T_{0}, \bar{T}(\tau)$-начальная и средняя текущая температуры зерна, К.

Левая часть этого равенства представляет теплоту, отдаваемую зерну при конденсации пара, а правая - теплоту, идущую на нагрев зерна.

Выделим из этого равенства текущее влагосодержание:

$$
U(\tau)=U_{H}+\frac{c_{3} \times \rho_{3} \times\left(\bar{T}(\tau)-T_{0}\right)}{r \times \rho_{n}}
$$

В соответствие с теорией тепломассопереноса [13], среднеобъёмную относительную температуру зерна $\bar{\Theta}$ можно найти из выражения

$$
\bar{\Theta}=\frac{\bar{T}(\tau)-T_{0}}{T-T_{0}}=1-\sum_{n=1}^{\infty} B_{n} \times \exp \left(-\mu_{n}^{2} \times \frac{a}{R^{2}} \times \tau\right)
$$

где $T$ - температура пара, К; $B_{n}$ - постоянные коэффицциенты [13];

$\mu_{n}$ - корни характеристического уравнения, получаемого при решении дифференциального уравнения теплопроводности с начальными и граничными условиями третьего рода [13];

a - коэффициент температуропроводности, $\mathrm{M}^{2} / \mathrm{c}$;

$R$ - определяющий размер зерновки, м.

Найдя отсюда $\bar{T}(\tau)$ и подставив в (1), получим

$$
U(\tau)=U_{\mathrm{H}}+\frac{c_{3} \times \rho_{3} \times\left(T-T_{0}\right) \times\left[1-B_{n} \times \exp \left(-\mu_{n}^{2} \times \frac{a}{R^{2}} \times \tau\right)\right]}{\rho_{\mathrm{n}} \times r}
$$

Используя последнее выражение, можно определить текущее или избыточное увлажнение зерна при его ГТО в любой момент времени, при этом корни характеристического уравнения можно вычислить методом последовательных приближений [14].

Следует отметить, что параметры а и $R$ в процессе увлажнения зерна гречихи также могут изменяться, что ставит под сомнение корректность использования их значений, соответствующих начальным или некоторым средним условиям. На наш взгляд, поиск таких результатов в указанном направлении вряд ли оправдан с точки зрения практической ценности, для которой значительно более важны были бы исследования кинетики увлажнения зерна в зависимости не только от времени, но и от других параметров процесса. Такая модель кинетики увлажнения зерна могла бы быть более полезной и в значительной мере способствовать как автоматизации процесса гидротермической обработки зерна, так и производству крупы высокого качества.

Здесь можно отметить, что ожидаемая эффективность результатов проведения сложных математических расчетов на базе современной вычислительной техники может оказаться невысокой, поскольку значения параметров, характеризующих фризико-химические свойства зерна, зависят от большого числа различных факторов и обычно известны с невысокой степенью точности. Поэтому более целесообразным, на наш взгляд, видится применение упрощённых математических моделей, сохраняющих лишь наиболее существенные отличительные признаки процесса увлажнения зерна, допускающих более высокую приближённость технологических оценок, но позволяющих более удобно 
интерпретировать результаты исследований и наглядно представить наиболее существенные тенденции изменения увлажнения зерна в процессе его гидротермической обработки при варьировании ее параметров [15]

Процесс подбора эмпирической модели кинетики увлажнения зерна заключается в выборе вида функциональной зависимости, а затем в определении численных значений параметров, для которых приближение к данному виду функции оказывается наилучшим.

Принимая во внимание возможность управления тремя параметрами при использовании предложенного нами способа пропаривания зерна гречихи перегретым паром и исследовании кинетики его увлажнения, можно применять трехфакторное моделирование процесса методами планирования эксперимента. Однако применение этого достаточно хорошо известного метода для получения нелинейной модели кинетики увлажнения зерна может оказаться затруднительным или невыполнимым практически.

Учитывая изложенное выше, а также характер выражения (4), нам представляется возможным использовать эмпирическую модель кинетики увлажнения зерна гречихи при гидротермической обработке предложенным способом в виде

$$
\frac{U(\tau)-U_{\mathrm{H}}}{U_{\text {пред }}-U_{\text {н }}}=\left[1-\exp \left(-k \times p^{m} \times T^{n} \times \tau\right)\right]
$$

где $U_{\text {пред }}$ - влагосодержание, соответствующее состоянию насыщения зерна влагой, кг/кг;

p- давление пара, Па;

$T$ - время, с;

$k, m, n-$ эмпирические коэфффициенты.

Подобрав $k, m$ и $n$ с наилучшим приближением кривой (5) к опытным данным методом средних [16], получим модель процесса увлажнения зерна в простом и удобном для интерпретации виде.

Выбранные коэффрициенты позволяют выявить влияние включенных в модель увлажнения параметров на процесс ГТО и минимизировать энерго- и ресурсозатраты при последующих после пропаривания технологических операциях обработки зерна.

Особенностью увлажнения зерна является наличие лимитирующей стадии, идущей значительно медленнее других и ограничивающей скорость всего процесса. При этом кривая увлажнения зерна, рассчитанная по выражению (5), будет иметь характерный для этого процесса вид (рисунок 1) монотонно возрастающей функции, асимптотически приближающейся к некоторому значению $U_{\text {пред, }}$ связанному с насыщением зерна влагой при тех или иных способах увлажнения.

Очевидно, что исследования процесса увлажнения целесообразно ограничивать временем, когда значение влажности зерна

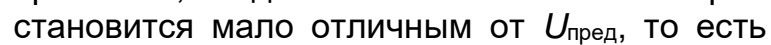
практически постоянным.

При увлажнении зерна насыщенным паром влияющим фрактором в показателе экспоненты выражения (5) будет помимо времени только давление пара, так как в этом случае оно связано с температурой фрунционально.

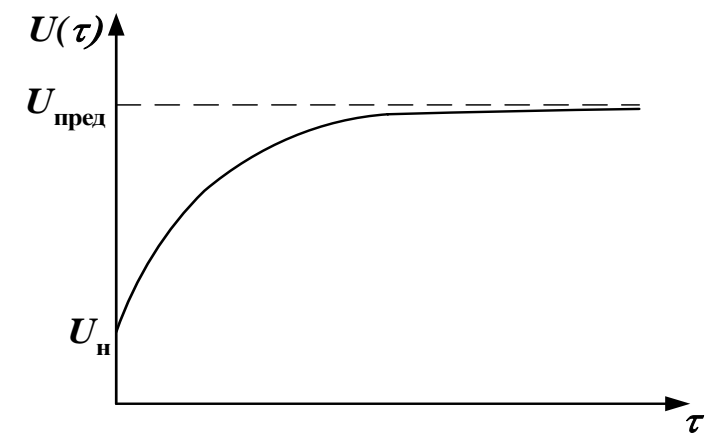

Рисунок 1 - Процесс увлажнения зерна

В зависимости от целей и задач, преследуемых при изучении кинетики увлажнения зерна, в качестве воздействующих на нее исследуемых параметров могут быть приняты и другие показатели, такие как начальные температура и влажность, а также крупность исходного зерна, характеристики пульсирующей подачи пара в случае ее использования и так далее.

Таким образом, кинетику увлажнения зерна рационально моделировать с помощью упрощенных математических функций, обеспечивающих приемлемую точность и удобство интерпретации. Предлагаемый тип модели процесса увлажнения зерна позволяет включать самые различные исследуемые факторы, которые поддаются количественной оценке, а также упростить программное обеспечение при автоматизации процесса гидротермической обработки зерна крупяных культур.

\section{СПИСОК ЛИТЕРАТУРЫ}

1. Мельников, Е. М. Технология крупяного производства / Е. М. Мельников. - М. : Агропромиздат, 1991. - 207 с.

2. Егоров, Г. А. Технология муки. Технология крупы / Г. А. Егоров. - М. : Колос, 2005. - 296 с. 


\section{МАТЕМАТИЧЕСКАЯ МОДЕЛЬ КИНЕТИКИ УВЛАЖНЕНИЯ ЗЕРНА КРУПЯНЫХ КУЛЬТУР ПРИ ГИДРОТЕРМИЧЕСКОЙ ОБРАБОТКЕ}

3. Бутковский, В. А. Технология зерноперерабатывающих производств / В. А. Бутковский, А. И. Мерко, Е. М. Мельников. - М. : Интерграф сервис, 1999. $-472 \mathrm{c}$.

4. Князева, О. Н. Разработка рациональной технологии производства гречневой крупы для гречеперерабатывающих предприятий малой мощности : автореф. дис. ... канд. техн. наук / О. Н. Князева - М. : ВГТА, 1997. - 24 с.

5. Влияние параметров температурной обработки на фризико-химический состав зерна гречихи / В. А. Марьин [и др.] // Южно-Сибирский научный вестник. - 2015. - № 4 (12). - С. 56-59.

6. Калашников, Г. В. Интенсивность влаготеплового воздействия при осциллированной влаготепловой обработке сыпучего продукта / Г. В. Калашников, В. Е. Добромиров // Вестник Воронежской государственной технологической академии. - 2009. - № 1. - С. 39-43.

7.Способ переработки зерна риса в крупу : пат. 2040965 Рос. Федерация: МПК В02В1/00 / Егоров Г. А., Щеголева И. Д., Саулькин В. И.; заявители Егоров Г. А., Щеголева И. Д., Саулькин В. И.; патентообладатель Егоров Глеб Александрович. - № 93045172/13; заявл. 10.09.1993; опубл. 09.08.1995.

8. Манаенков, В. В. Увлажнение риса-зерна при водно-тепловой обработке / В. В. Манаенков [и др.] // Труды ВНИИЗ. - 1991. - № 115. - С. 107111.

9. Анисимова, Л. В. Распределение влаги в зерне крупяных культур при увлажнении и отволаживании / Л. В. Анисимова // Изв. вузов. Пищ. технол. -2005 . - № 1. - С. 60-62.

10. Иунихина, В. С. Кинетика изменения влажности колотого ядра овса при пропаривании
/ В. С. Иунихина, И. Л. Виноградова // Хранение и переработка зерна. - 2003. - №1. - С. 41-42.

11. Аюшеева, О. Г. Математическая модель влаготепловой обработки гречихи / О. Г. Аюшеева, В. Д. Раднаева // Техника и технологии продуктов питания: Наука. Образование. Достижения. Инновации: мат. межд. научно-практ. конф. Улан-Удэ : Изд-во ВСГУТУ, 2014, - С. 71-75.

12. Способ гидротермической обработки зерна гречихи : пат. 28803 Казахстан: МПК В 02 В 1/08/ Н. А. Борзов, А. А. Румянцев; заявитель и патентообладатель Н. А. Борзов, А.А. Румянцев. - № 2013/1271.1; заявл. 09.09.2013; опубл. 15.08.2014, Бюл. № 8.

13. Лыков, А. В. Тепломассообмен / А. В. Лыков. - М. : Энергия, 1978. - 479 с.

14. Михайлов, Ю. А. Тепломассоперенос / Ю. А. Михайлов. - Минск : Энергия, 1972. - 200 с.

15. Оспанов, А. Моделирование процесса увлажнения зерна при гидротермической обработке / А. Оспанов, А. Румянцев, Н. Борзов // Хлебопродукты. - 2008. - № 4. - С. 56-57.

16. Грачев, Ю. П. Моделирование и оптимизация тепло- и массообменных процессов пищевых производств / Ю. П. Грачев, А. К. Тубольцев, В. К. Тубольцев. - М. : Легк. и пищ. пром-сть, 1984. $-216 \mathrm{c}$.

Румянцев Александр Алексеевич, канд. техн. наук, доцент кафредры пищевой инженерии аграрного производства, ФГБОУ ВО «Уральский государственный аграрный университет», 620075, Россия, г. Екатеринбура, ул. Карла Либкнехта 42, e-mail: rumyansev@rambler.ru, тел.: (343) 221-41-10. 